\title{
Water sorption and solubility of bulk-fill composites polymerized with a third generation LED LCU
}

Tuğba MisilLij(a)

Nihan GÖNÜLOL(b)

(a)Balıkesir Oral and Dental Health Center, Balıkesir, Turkey.

(b) Ondokuz Mayıs University, Faculty of Dentistry, Department of Restorative Dentistry, Samsun, Turkey

Declaration of Interest: The authors certify that they have no commercial or associative interest that represents a conflict of interest in connection with the manuscript.

Corresponding address:

Nihan GÖNÜLOL

E-mail: nihan.gonulol@omu.edu.tr

htrps://doi.org/10.1590/1807-3107BOR-2017.vol31.0080

Submitted: Apr 25, 2017

Accepted for publication: July 02, 2017

Last revision: Aug 14, 2017
Abstract: The aim of this study was to compare the degree of water sorption and solubility in bulk-fills after curing with a polywave light source. A total of 120 disc-shaped specimens ( $8 \mathrm{~mm}$ diameter; $4 \mathrm{~mm}$ depth) were prepared from three regular bulk-fill materials (X-tra Fil, Tetric N-Ceram Bulk Fill, SonicFill), and a control material (Filtek Z250), cured in 3 different modes (standard: $1000 \mathrm{~mW} / \mathrm{cm}^{2}-20 \mathrm{~s}$; high power: $1400 \mathrm{~mW} / \mathrm{cm}^{2}-12 \mathrm{~s}$; xtra power: $3200 \mathrm{~mW} / \mathrm{cm}^{2}-6 \mathrm{~s}$ ) using a third generation light-emitting diode light curing unit. Water sorption and solubility levels of the specimens were measured according to the ISO 4049:2009 specification after storing in distilled water for 30 days. Data were analyzed using two-way ANOVA and Tukey's post-hoc test $(p<0.05)$. The Z250 sample exposed to high power presented a higher sorption compared to the X-tra Fil and SonicFill samples. In xtra power mode, the values of Z250 and SonicFill were similar to each other and higher compared to those of X-tra Fil. Only SonicFill exhibited significantly different sorption values depending on the curing mode, the highest of which was achieved when using the xtra power mode. The highest solubility values were obtained for SonicFill. No statistically significant differences were found among other groups. No significant correlation was detected between water sorption and solubility. The traditional composite group exhibited a higher water sorption values than the bulk-fills. The reduction in polymerization time significantly increased the sorption of SonicFill. SonicFill showed the highest water solubility value among the composites tested.

Keywords: Composite Resins; Curing Lights, Dental; Absorption; Solubility.

\section{Introduction}

Along with the recent advances in dental materials and clinical techniques, resin composites have become the most widely-used direct restorative materials to satisfy patients' aesthetic demands for the restoration of dental caries, crown fractures, congenital defects, and tooth wear. ${ }^{1}$ On the other hand, conventional composite resins have the disadvantages of a limited penetration depth of light ${ }^{2}$ and an observed structure shrinkage rate of $2-5 \%{ }^{3}$. Polymerization shrinkage generates stress at the tooth-composite interface. Thus, when shrinkage stress exceeds bond strength, debonding occurs at the interface. As a result, a number of clinical problems, such as microleakage, secondary caries, discoloration 
and postoperative sensitivity may arise. ${ }^{4}$ In order to minimize the volumetric polymerization shrinkage, so to reduce stress at the tooth-composite interface ${ }^{5}$ and achieve better mechanical properties along with adequate light penetration, ${ }^{2}$ an incremental technique is needed, in which the composite is layered and light cured in increments of less than $2 \mathrm{~mm}$. However, the incremental technique has a number of drawbacks, which include bond failures between increments due to contamination, the creation of voids, the more time required to place and polymerize each layer, and the difficulty in placement because of limited access during the conservative preparations. ${ }^{6}$

In an attempt to overcome problems stemming from the layering technique and to simplify the restoration process, manufacturers have worked to develop a composite resin that can be placed in bulk with an increased curing depth. For this purpose, a new resin-based composite material, bulk-fill composite, has been introduced to the market in recent years. Manufacturers claim that bulk-fills can be cured in thick increments of up to 4 or $5 \mathrm{~mm}$ in each step, with a lower polymerization shrinkage stress compared to conventional composite resins. As mentioned earlier, the main advantage of using bulk-fills is the possibility of increasing the curing depth; this is achieved by a higher translucency, resulting either from decreased filler load or increased filler size, which limits light scattering. The low shrinkage stress is due to modifications to the organic matrix and/or filler content. ${ }^{7}$

Bulk-fill composites are classified into two types, according to their mechanical properties and the application technique used, namely low-viscosity and regular bulk-fills. Low-viscosity bulk-fills are designed as a base material and require the placement of a final capping layer made of a regular composite material because of their low surface hardness and elasticity modulus. Regular bulk-fills do not need an additional capping layer and can be used as a singlestep filling material. ${ }^{5,8}$

With the spread of photopolymerizable dental composites, significant advances have been made in light curing units (LCUs) used in polymerization processes. Recently, the incorporation of different photoinitiators has led to the development of third generation polywave LED LCUs. ${ }^{9}$ Blue-violet LED curing units with high irradiance are proving to be promising for the fast polymerization of modern resin composites. Although there is no general consensus on the adequate radiant exposure a material needs for proper polymerization, the irradiance of modern curing units continues to increase, in agreement with the claim that an adequate polymerization might be reached at short exposure times and high irradiances. ${ }^{10}$ The third generation LED used in the present study provides shorter exposure times, depending on the chosen operating mode and therefore irradiances. ${ }^{11}$ The compatibility of the different modes of operation of these LCUs with bulk-fills has not yet been confirmed.

There is also concern that the product of the polymerization reaction carried out at short exposure time at high radiant exitance may be characterized by having short chains, with low molecular weight and fewer cross links. ${ }^{12}$ Cross linking provides a sufficient number of bridges between linear macromolecules to form a three-dimensional network, decreasing water sorption and solubility. This study, therefore, evaluated the effectiveness of third generation LED LCUs on the polymerization of current bulk-fills using water sorption and solubility tests as significant parameters.

The null test hypothesis was that there would be no significant difference between regular bulk-fill composite groups and the conventional composite group with regard to the degree of water sorption and solubility after polymerization using the third generation LED LCU at different curing modes.

\section{Methodology}

The three regular bulk-fill composites were used in the study, were X-tra Fil (Voco), Tetric N-Ceram Bulk Fill (Ivoclar Vivadent), and SonicFill (Kerr). Filtek Z250 (3M ESPE), a microhybrid composite resin, was used as a control group. Table 1 provides details of the materials. A third generation LED LCU (VALO, Ultradent) was used for polymerization.

Disc-shaped specimens, $4 \mathrm{~mm}$ thick and $8 \mathrm{~mm}$ in diameter, were prepared using Teflon molds. The specimens were divided into four main groups, depending on the resin composite used. All groups were then divided into three subgroups, defined on 
Table 1. Materials tested.

\begin{tabular}{|c|c|c|c|c|c|}
\hline Materials & Resin matrix & Filler & Filler content (wt.\%) & Shade & Manufacturer \& Lot no. \\
\hline Filtek $^{\text {TM }}$ Z250 & $\begin{array}{c}\text { Bis-GMA, Bis-EMA, } \\
\text { UDMA, TEGDMA }\end{array}$ & zirconium/silica & 82 & A2 & $\begin{array}{l}\text { 3M ESPE,St Paul, } \\
\text { MN, USA N602029 }\end{array}$ \\
\hline $\begin{array}{l}\text { Tetric }{ }^{\circledR} \text { N-Ceram } \\
\text { Bulk Fill }\end{array}$ & $\begin{array}{c}\text { Bis-GMA, Bis-EMA, } \\
\text { UDMA }\end{array}$ & $\begin{array}{c}\text { Ba glass, } \mathrm{PPF}, \mathrm{YbF}_{3} \text {, } \\
\text { oxide }\end{array}$ & $75-77$ & IVA & $\begin{array}{c}\text { Ivoclar Vivadent, } \\
\text { Schaan, Liechtenstein } \\
\text { T14296 }\end{array}$ \\
\hline X-tra fil & $\begin{array}{c}\text { Bis-GMA, UDMA, } \\
\text { TEGDMA }\end{array}$ & Ba-B-Al silicate & 86 & U & $\begin{array}{l}\text { VOCO, Cuxhaven, } \\
\text { Germany } 1447376\end{array}$ \\
\hline SonicFill ${ }^{\mathrm{TM}}$ & $\begin{array}{c}\text { Bis-GMA, } \\
\text { TEGDMA,Bis-EMA }\end{array}$ & $\mathrm{SiO}_{2}$, glass, oxide & 83.5 & A2 & $\begin{array}{c}\text { Kerr, Orange, CA, } \\
\text { USA } 35183\end{array}$ \\
\hline
\end{tabular}

Bis-GMA: bisphenol-A-glycidyldimethacrylate; Bis-EMA: ethoxylated bisphenol-A-dimethacrylate; UDMA: urethane dimethacrylate; TEGDMA: triethyleneglycol dimethacrylate; PPF: prepolymerized fillers. Other abbreviations according to periodic system of elements. Data are provided by manufacturers.

the basis of the light source adopted. A total of 120 samples ( $\mathrm{n}=10$ for each group) were prepared. Details of the study groups are shown in Table 2.

Samples were prepared by applying bulk-fills in one step, whereas the conventional composite was applied in the mold as two 2-mm-thick layers. After filling each mold with the material and covering it with a matrix strip (Hawe Stopstrip, Kerr), the top of the material was compressed using a glass slide. The top surface of the specimens was then lightcured, placing the light tip in contact with the glass slide to standardize the curing distance.

According to the manufacturers' instructions ${ }^{11}$, the bulk-fill composites were light cured once for $20 \mathrm{~s}$ in standard mode, 3 times for $4 \mathrm{~s}$ in high power mode, and twice for $3 \mathrm{~s}$ in xtra power mode. When using the conventional composite resin, polymerization was carried out as follows: the first layer was cured once for $10 \mathrm{~s}$ in standard mode, twice for $4 \mathrm{~s}$ in high power mode, and once for $3 \mathrm{~s}$ in xtra power mode; the second layer was cured once for $20 \mathrm{~s}$ in standard power mode, three times for $4 \mathrm{~s}$ in high power mode, and twice for $3 \mathrm{~s}$ in xtra power mode. Curing modes and times are shown in Table 3. The LED LCU was used fully charged and the value specified by the manufacturer was used in subsequent calculations.

The total radiant exposure $\left(\mathrm{mJ} / \mathrm{cm}^{2}\right)$ applied to the composite resins was determined by multiplying the radiant exitance $\left(\mathrm{mW} / \mathrm{cm}^{2}\right)$ by the exposure time $(\mathrm{s})$, as shown below:

standard mode $=1,000 \times 20=20 \mathrm{~J} / \mathrm{cm}^{2}$

high power mode $=1,400 \times 12=16.8 \mathrm{~J} / \mathrm{cm}^{2}$

xtra power mode $=3,200 \times 6=19.2 \mathrm{~J} / \mathrm{cm}^{2}$
Table 2. Study groups.

\begin{tabular}{lcc}
\hline Groups & $\begin{array}{c}\text { Subgroups } \\
\text { according to modes }\end{array}$ & Number of sample \\
\hline Z250 (control) & standard & 10 \\
& high power & 10 \\
& xtra power & 10 \\
X-tra Fil & standard & 10 \\
& high power & 10 \\
& xtra power & 10 \\
Tetric N-Ceram & standard & 10 \\
& high power & 10 \\
Stra power & 10 \\
standard & 10 \\
& high power & 10 \\
\hline
\end{tabular}

Table 3. Curing modes and exposure times.

\begin{tabular}{lccc}
\hline LCU/Manufacturer & \multicolumn{2}{c}{$\begin{array}{c}\text { VALO/Ultradent Products Inc., } \\
\text { South Jordan, UT, USA }\end{array}$} \\
\hline Mode & Standard & High power & Xtra power \\
\hline $\begin{array}{l}\text { Irradiance }\left(\mathrm{mW} / \mathrm{cm}^{2}\right) \\
\text { Conventional composite }\end{array}$ & 1,000 & 1,400 & 3,200 \\
first layer & $1 \times 10 \mathrm{~s}$ & $2 \times 4 \mathrm{~s}$ & $1 \times 3 \mathrm{~s}$ \\
second layer & $1 \times 20 \mathrm{~s}$ & $3 \times 4 \mathrm{~s}$ & $2 \times 3 \mathrm{~s}$ \\
Bulk-fill composites & & & \\
single layer & $1 \times 20 \mathrm{~s}$ & $3 \times 4 \mathrm{~s}$ & $2 \times 3 \mathrm{~s}$ \\
\hline
\end{tabular}




\section{Measurement of water sorption and solubility values}

The sorption and solubility tests were performed in compliance with the ISO 4049:2009 standards. The specimens were inserted into a desiccator containing freshly dried white silica and maintained at $37 \pm 1^{\circ} \mathrm{C}$ for $22 \mathrm{~h}$ and at $23 \pm 1^{\circ} \mathrm{C}$ for 2 additional hours. Specimens were then weighed to an accuracy of $0.0001 \mathrm{~g}$, using an analytical balance (Precisa XB 220A, Zurich, Switzerland). This cycle was repeated until the mass loss of each specimen was lower than $0.1 \mathrm{mg}$ in any $24 \mathrm{~h}$ period. This constant mass, $\mathrm{M}_{1}$, was taken as the initial mass of the specimen and was expressed in micrograms ( $\mu \mathrm{g})$. After final drying, the thickness and diameter of each specimen were measured using a digital caliper (C-master, Mitutoyo, Tokyo, Japan) and the average volume (V) of samples was calculated in cubic millimeters $\left(\mathrm{mm}^{3}\right)$.

Each specimen was immersed in distilled water for 30 days at $37 \pm 1^{\circ} \mathrm{C}$ and kept in an oven. After completing the storage period, the specimens were removed, gently dried with absorbent paper, and weighed again to obtain the mass $\mathrm{M}_{2}$. Thereafter, the specimens were reconditioned in the desiccator until they reached a constant weight $\left(\mathrm{M}_{3}\right)$ using the same cycle described for $M_{1}$. The values for water sorption $\left(\mathrm{W}_{\mathrm{sp}}\right)$ and solubility $\left(\mathrm{W}_{\mathrm{sl}}\right)$, expressed in micrograms per cubic millimeter, were calculated using the following formulae: $\mathrm{W}_{\mathrm{sp}}=\left(\mathrm{M}_{2}-\mathrm{M}_{3}\right) / \mathrm{V}$; $\mathrm{W}_{\mathrm{sl}}=\left(\mathrm{M}_{1}-\mathrm{M}_{3}\right) / \mathrm{V}$.

\section{Statistical analysis}

The mean $W_{\mathrm{sp}}$ and $\mathrm{W}_{\mathrm{sl}}$ values of different materials were compared using two-way ANOVA, followed by Tukey post-hoc analysis for multiple comparisons. Pearson's correlation test was used to assess the relationship between $\mathrm{W}_{\mathrm{sp}}$ and $\mathrm{W}_{\mathrm{sl}}$ values. $\mathrm{p}<0.05$ was considered to indicate statistical significance.

\section{Results}

Table 4 presents the results for $\mathrm{W}_{\mathrm{sp}}$. Two-way ANOVA defined the statistical significance of the two main factors: resin composite $(p<0.001)$ and curing mode ( $\mathrm{p}=0.001)$, as well as for the interaction between the two $(p=0.004)$. The comparison of the same composite group at different curing modes showed that only SonicFill exhibited significantly different $\mathrm{W}_{\mathrm{sp}}$ values depending on the curing mode and reached the highest value when using the xtra power mode $(p<0.001)$. When composites treated with the same curing mode were compared, it was found that Z250 exposed to the high power mode presented a higher sorption value than $X$-tra Fil and SonicFill ( $p<0.001$ ). The sorption values of $Z 250$ and SonicFill exposed to $x$ tra power mode were similar and higher than that of the X-tra Fil $(p=0.007$ and $p=0.016$, respectively). When using the standard mode, the composite groups did not differ from each other $(p=0.243)$.

The results for $\mathrm{W}_{\mathrm{sl}}$ are shown in Table 5. Two-way ANOVA detected a significant influence for only one of the main factors: resin composite ( $p<0.001)$. On the other hand, the curing mode $(p=0.205)$ and interaction $(p=0.408)$ were shown to not be significant. According to overall averages of composite groups, SonicFill exhibited the highest solubility values ( $p<0.001)$. There was no significant difference between $X$-tra Fil, Z250 and Tetric N-Ceram ( $\mathrm{p}=0.484)$. Also, the behavior of composites was the same, irrespective of the curing modes.

There was no correlation between $\mathrm{W}_{\mathrm{sp}}$ and $\mathrm{W}_{\mathrm{sl}}$ in the tested materials $(\mathrm{r}=-0.003, \mathrm{p}=0.974)$.

\section{Discussion}

The oral cavity is a dynamic environment. Restorative materials are expected to function effectively for a long time in the oral environment, where they are exposed to moisture, variable

Table 4. Means and standard deviations ( $\pm \mathrm{sd}$ ) of $\mathrm{W}_{\mathrm{sp}}$ in $\mu \mathrm{g} / \mathrm{mm}^{3}$.

\begin{tabular}{|c|c|c|c|}
\hline \multirow{2}{*}{ Groups } & \multicolumn{3}{|c|}{ Curing modes (mean \pm sd) } \\
\hline & standard & high power & xtra power \\
\hline Z250 & $13.95 \pm 1.81^{\mathrm{A}, \mathrm{B}}$ & $18.81 \pm 5.77^{\mathrm{A}}$ & 18.15 \\
\hline X-tra Fil & $11.34 \pm 2.16^{B}$ & $12.02 \pm 2.34^{B}$ & $11.61 \pm 2.31^{B}$ \\
\hline $\begin{array}{l}\text { Tetric } \\
\text { N-Ceram }\end{array}$ & $13.54 \pm 1.41^{A, B}$ & $15.10 \pm 4.87^{A, B}$ & $14.26 \pm 2.57^{A, B}$ \\
\hline SonicFill & $10.67 \pm 3.05^{\mathrm{B}}$ & $11.14 \pm 4.07^{\mathrm{B}}$ & $17.71 \pm 5.56^{\mathrm{A}}$ \\
\hline
\end{tabular}

Superscripts represent the statistical significance. Means followed by the same letters are statistically similar. 
Table 5. Means and standard deviations ( $\pm \mathrm{sd}$ ) of $\mathrm{W}_{\mathrm{sl}}$ in $\mu \mathrm{g} / \mathrm{mm}^{3}$.

\begin{tabular}{lcccc}
\hline Groups & \multicolumn{3}{c}{ Curing modes (mean $\pm \mathrm{sd}$ ) } & $\begin{array}{c}\text { Material average } \\
\text { (mean } \pm \mathrm{sd} \text { ) }\end{array}$ \\
\cline { 2 - 4 } Z250 & $-2.75 \pm 1.48$ & high power & xtra power & $-2.63 \pm 0.99 \mathrm{~b}$ \\
X-tra Fil & $-2.50 \pm 0.73$ & $-2.70 \pm 0.67$ & $-2.45 \pm 0.69$ & $-2.57 \pm 0.56^{\mathrm{b}}$ \\
Tetric N-Ceram & $-2.64 \pm 1.01$ & $-2.65 \pm 0.57$ & $-2.55 \pm 0.38$ & $-2.93 \pm 1.16^{\mathrm{b}}$ \\
SonicFill & $0.57 \pm 1.11$ & $-3.17 \pm 1.66$ & $-2.96 \pm 0.65$ & $0.94 \pm 1.10^{\circ}$ \\
Curing mode average & $-1.83 \pm 1.77$ & $-1.97 \pm 1.88$ & $1.61 \pm 0.46$ & $-1.80 \pm 1.86$ \\
\hline
\end{tabular}

Superscripts represent the statistical significance. Means followed by the same letters are statistically similar.

temperature conditions, and repetitive mechanical forces. ${ }^{13,14}$ However, resin composites are not stable even after polymerization and constantly interact with their environment. The main interaction is with water, which diffuses into the matrix. ${ }^{15}$

Polymers absorb water to different degrees, depending on their microstructural and molecular aspects. The degree of water sorption is influenced by the polarity of the molecular structure, the presence of hydroxyl groups capable of forming hydrogen bonds with water, and the degree of cross linking in the continuous matrix. ${ }^{14}$ The uptake of water may result in an expansion of the gap between polymer chains, depending on the degree of cross-link density in its structure. This allows free unreacted components trapped in the polymer network to diffuse out, into the storage solvent, depending on their molecular size and affinity towards the aqueous solvent. ${ }^{16,17}$ The solubility behavior of dental materials is affected by the type of storage medium and the immersion period. When the previous factors are standard, behavior will also be affected by the type, rate, and surface area of the filler used, the particular silane treatment, the difference in the monomer structure, and the degree of cross linking. ${ }^{18}$ Residual monomers, fillers, degradation products or inhibitors and activators of polymerization are therefore able to leach out from cured resin-based materials. As a result, water sorption and solubility have a significant effect on the clinical success of restorative material, influencing the aesthetic appearance, integrity, and surface properties. ${ }^{14}$

According to the ISO 4049 standard, the $\mathrm{W}_{\mathrm{sp}}$ and $W_{\mathrm{sl}}$ values must be lower than $40 \mu \mathrm{g} / \mathrm{mm}^{3}$ and $7,5 \mu \mathrm{g} / \mathrm{mm}^{3}$, respectively. ${ }^{19}$ The $W_{\mathrm{sp}}$ and $\mathrm{W}_{\mathrm{sl}}$ values obtained in this study using the standard formula were considerably lower than the threshold values for all composites tested. When we examined these values, for all composite groups and irradiation protocols, it was found that the highest $\mathrm{W}_{\mathrm{sp}}$ value was obtained by Filtek Z250 in high power mode $\left(18.81 \pm 5.77 \mu \mathrm{g} / \mathrm{mm}^{3}\right)$, whereas the SonicFill group showed the highest $\mathrm{W}_{\mathrm{sl}}$ value when treated in xtra power mode $\left(1.61 \pm 0.46 \mu \mathrm{g} / \mathrm{mm}^{3}\right)$.

$\mathrm{W}_{\mathrm{sp}}$ values had a negative correlation with the amount of filler content, in line with previous studies. ${ }^{20}$ X-tra Fil, which had the highest filler rate, had the lowest $\mathrm{W}_{\mathrm{sp}}$ value, followed by SonicFill, Tetric N-Ceram Bulk Fill, and Filtek Z250, respectively. This situation can be explained by the fact that the polymeric matrix decreases as the weight percentage of filler increases, with a consequent decrease in water sorption, which is mainly associated with the polymeric phase. ${ }^{17}$ Oysaed and Ruyter ${ }^{13}$ examined the characteristics of eight different composites and reported that $W_{\mathrm{sp}}$ and $W_{\mathrm{sl}}$ values decrease as the filler ratio increases. At the same time, with a large filler surface area, the presence of voids in the structure causes an increase in sorption.

On the other hand, although it contains a lower filler loading, Tetric N-Ceram Bulk Fill contains some prepolymerized fillers, ${ }^{21}$ unlike the other materials used in this study. This feature may have conferred to Tetric N-Ceram similar water sorption properties as Filtek Z250.

The total energy transmitted to the resin has an effect on the degree of cure and is calculated by multiplying radiant exitance with exposure time. ${ }^{12,22,23,24}$ The degree of conversion is an another factor that has an impact on water sorption. ${ }^{17}$ When 
the composite groups were examined individually at different curing modes, the highest $\mathrm{W}_{\mathrm{sp}}$ values were obtained when applying the high power mode $\left(1,400 \mathrm{~mW} / \mathrm{cm}^{2}-12 \mathrm{~s}\right)$ to Filtek Z250, X-tra Fil and Tetric $\mathrm{N}$-Ceram Bulk Fill. The higher water sorption values observed at high power mode may be related to the low radiant exposure values $\left(16.8 \mathrm{~J} / \mathrm{cm}^{2}\right)$ delivered to materials. However, the difference between $\mathrm{W}_{\mathrm{sp}}$ values at different modes of these composites was not statistically significant. On the other hand, a significantly higher $\mathrm{W}_{\mathrm{sp}}$ value was obtained at xtra power mode for the SonicFill group, although the radiant exposure obtained $\left(19.2 \mathrm{~J} / \mathrm{cm}^{2}\right)$ was very close to the one achieved in the standard mode $\left(20 \mathrm{~J} / \mathrm{cm}^{2}\right)$. This supports the concern of Rueggeberg ${ }^{12}$ that a short exposure time at high radiant exitance may result in the formation of short chains, which contain fewer cross links. Peutzfeldt and Asmussen ${ }^{24}$ have also pointed out that the degree of cure increases with increasing radiant exposure, but decreases with short exposure time at high radiant exitance, despite achieving the same energy density. Halvorson et al. ${ }^{23}$ concluded that the reciprocal relationship between radiant exitance and exposure duration is invalid when exposure time is short. The higher sorption value at xtra power mode in comparison with the standard mode for SonicFill can be explained with the results of these previous studies. Furthermore, Filtek Z250 showed higher sorption values when exposed to high and xtra power mode compared to the other composites. This may be related to the low radiant exposure value delivered to the first layer of Filtek Z250 because of the different application methods adopted for the conventional composite and bulk-fills.

Water sorption and solubility studies have generally revealed that $W_{s p}$ and $W_{s l}$ values change in the same way. ${ }^{25}$ Many researchers ${ }^{16,18,26}$ have determined that materials with low sorption demonstrate low solubility. Some studies, however, suggest that materials with high water sorption do not necessarily demonstrate high solubility, ${ }^{27}$ as shown here.

In this study, filler content does not have the same effect on solubility while maintaining an important role in sorption. In addition, the solubility values obtained for composites do not depend only on resin structure or filler content. The main components released from a resin composite are free residual monomers. ${ }^{14}$ The amount of leachable residual monomers is highly dependent on the degree of cure. Consequently, a higher curing degree leads to a lower number of unreacted monomers and a lower solubility level. ${ }^{16}$ The molecular size of the monomer is an another important factor in the dissociation of residual monomers, as the smaller molecules will decompose faster. Lower weight monomers can be decomposed in greater amounts than higher weight monomers. ${ }^{28}$ TEGDMA is a low molecular weight monomer, which shows high mobility and decomposes more quickly than larger molecules, such as Bis-GMA. ${ }^{29}$ In our study, all composites, with the exception of Tetric N-Ceram Bulk Fill, contain TEGDMA in the organic matrix structure. Filtek Z250 also has a small amount of TEGDMA in the structure. The results of the present study also showed that the $\mathrm{W}_{\mathrm{sl}}$ value was lowest in Tetric N-Ceram Bulk Fill, followed by Filtek Z250, X-tra Fil, and SonicFill. In addition, the differences between the composite groups were not significant, with the exception of SonicFill, which showed the highest solubility value. Moreover, the behavior of composites was the same, irrespective of the curing modes. These outcomes are compatible with the results reported by Ilie and Stark ${ }^{10}$, who observed that to maintain the mechanical properties at a 4-mm depth, a higher radiant exposure is required by SonicFill compared to the other bulk-fills. The importance of light intensity and efficiency increases with the increasing depth of resin in photopolymerizable dental composites. ${ }^{22}$ When researchers investigated the amount of radiant exposure required for adequate polymerization, they reported that SonicFill reflected light with low translucency ${ }^{10}$. This characteristic could explain the high solubility value of the material and has been justified in terms of the irregular shapes of the fillers in its structure. It has also been suggested that the difference in translucency between polymerized and unpolymerized materials was very low in this material, indicating that the reduced light transmission is caused by the mismatch between the refractive index at the matrix-filler interface. ${ }^{30}$

In this study, negative $W_{s l}$ values were obtained for all groups, except for the SonicFill. Considering 
the possibility of incomplete dehydration of the materials, these negative values may be indicative of a low level of solubility rather than the complete absence of dissolution. Negative solubility results have also been reported in other studies. ${ }^{18,31,32}$ In some studies, these negative values have been explained by possible hydrolytic chemical reactions that result in the formation of metal hydroxides on the filler surface. ${ }^{18}$ In other studies, it has been suggested that negative values may be the result of hydrogen bonds connecting the absorbed water molecules to polar groups of the polymer chains, which cannot be removed entirely. ${ }^{31,32}$

As a result, Filtek Z250 showed higher water sorption values in all curing modes when compared with bulkfill composites. In terms of water solubility, the SonicFill bulk-fill composite showed the highest value among the groups, so that the null hypothesis was rejected.

\section{Conclusion}

Within the limitations of this study, the following conclusions can be drawn:

\section{References}

1. Kwon Y, Ferracane J, Lee IB. Effect of layering methods, composite type, and flowable liner on the polymerization shrinkage stress of light cured composites. Dent Mater. 2012;28(7):801-9. https://doi.org/10.1016/i.dental.2012.04.028

2. Yap AU. Effectiveness of polymerization in composite restoratives claiming bulk placement: impact of cavity depth and exposure time. Oper Dent. 2000;25(2):113-20.

3. Kleverlaan CJ, Feilzer AJ. Polymerization shrinkage and contraction stress of dental resin composites. Dent Mater. 2005;21(12):1150-7. https://doi.org/10.1016/i.dental.2005.02.004

4. Kim RJ, Son SA, Hwang JY, Lee IB, Seo DG. Comparison of photopolymerization temperature increases in internal and external positions of composite and tooth cavities in real time: incremental fillings of microhybrid composite vs. bulk filling of bulk fill composite. J Dent. 2015;43(9):1093-8. https://doi.org/10.1016/i.jdent.2015.07.003

5. Kim RJ, Kim YJ, Choi NS, Lee IB. Polymerization shrinkage, modulus, and shrinkage stress related to tooth-restoration interfacial debonding in bulk-fill composites. J Dent. 2015;43(4):430-9. https://doi.org/10.1016/i.jdent.2015.02.002

6. Abbas G, Fleming GJ, Harrington E, Shortall AC, Burke FJ. Cuspal movement and microleakage in a. Water sorption and solubility values are affected by the filler ratio and type of resin matrix, regardless of the composite type. The regular bulk-fills used in this study exhibited significantly better properties compared to conventional composite in terms of water sorption.

b. When the performance of bulk-fills was considered, the xtra power mode for SonicFill resulted in the worst performance in terms of water sorption. In the SonicFill group, this was also true for solubility, irrespective of the curing modes. As a result, the xtra power mode is not considered beneficial for curing in a short time period, especially for SonicFill.

\section{Acknowledgments}

This study was financially supported by The Scientific and Technological Research Council of Turkey with Project no:114S991.

premolar teeth restored with a packable composite cured in bulk or in increments. J Dent. 2003;31(6):437-44. https://doi.org/10.1016/S0300-5712(02)00121-5PMID:12878027

7. Leprince JG, Palin WM, Vanacker J, Sabbagh J, Devaux J, Leloup G. Physico-mechanical characteristics of commercially available bulk-fill composites. J Dent. 2014;42(8):993-1000. https://doi.org/10.1016/i.jdent.2014.05.009

8. Tarle Z, Attin T, Marovic D, Andermatt L, Ristic M, Tauböck TT. Influence of irradiation time on subsurface degree of conversion and microhardness of high-viscosity bulk-fill resin composites. Clin Oral Investig. 2015;19(4):831-40. https://doi.org/10.1007/s00784-014-1302-6

9. Jandt KD, Mills RW. A brief history of LED photopolymerization. Dent Mater. 2013;29(6):605-17. https://doi.org/10.1016/j.dental.2013.02.003

10. Ilie N, Stark K. Curing behaviour of high-viscosity bulk-fill composites. J Dent. 2014;42(8):977-85. https://doi.org/10.1016/i.jdent.2014.05.012

11. Ultradent Products, Inc. VALO cordless: introduction for use. South Jordan: Ultradent; 2012 [cited 2015 Dec 8]. Available from: http://www.valo-led.com/Lists/Product\%20Resources/ VALO\%20Cordless.pdf 
12. Rueggeberg F. Contemporary issues in photocuring. Compend Contin Educ Dent Suppl. 1999 25(25):S4-15.

13. Oysaed H, Ruyter IE. Water sorption and filler characteristics of composites for use in posterior teeth. J Dent Res. 1986;65(11):1315-8. https://doi.org/10.1177/00220345860650110601

14. Mortier E, Gerdolle DA, Jacquot B, Panighi MM. Importance of water sorption and solubility studies for couple bonding agents: resin-based filling material. Oper Dent. 2004;29(6):669-76.

15. Thonemann BM, Federlin M, Schmalz G, Hiller KA. SEM analysis of marginal expansion and gap formation in Class II composite restorations. Dent Mater. 1997;13(3):192-7. https://doi.org/10.1016/S0109-5641(97)80026-7

16. Sideridou I, Tserki V, Papanastasiou G. Study of water sorption, solubility and modulus of elasticity of light-cured dimethacrylate-based dental resins. Biomaterials. 2003;24(4):655-65. https://doi.org/10.1016/S0142-9612(02)00380-0

17. Ferracane JL. Hygroscopic and hydrolytic effects in dental polymer networks. Dent Mater. 2006;22(3):211-22. https://doi.org/10.1016/i.dental.2005.05.005

18. Ortengren $U$, Wellendorf H, Karlsson S, Ruyter IE. Water sorption and solubility of dental composites and identification of monomers released in an aqueous environment. J Oral Rehabil. 2001;28(12):1106-15. https://doi.org/10.1046/i.1365-2842.2001.00802.x

19. Heintze SD, Zimmerli B. Relevance of in vitro tests of adhesive and composite dental materials, a review in 3 parts. Part 1: approval requirements and standardized testing of composite materials according to ISO specifications. Schweiz Monatsschr Zahnmed. 2011;121(9):804-16.

20. Alshali RZ, Salim NA, Satterthwaite JD, Silikas N. Long-term sorption and solubility of bulk-fill and conventional resin-composites in water and artificial saliva. J Dent. 2015;43(12):1511-8. https://doi.org/10.1016/i.jdent.2015.10.001

21. Ivoclar Vivadent Pty. Ltd. Scientific Documentation Tetric ${ }^{\circledR}$ N-Ceram Bulk Fill [cited 2015 Nov 9]. Available from: http://www.ivoclarvivadent.com.tr/tr/tetric-n-ceram-bulk-fill.

22. Vargas MA, Cobb DS, Schmit JL. Polymerization of composite resins: argon laser vs. conventional light. Oper Dent 1998;23(2):87-93.
23. Halvorson RH, Erickson RL, Davidson CL. Energy dependent polymerization of resin-based composite. Dent Mater. 2002;18(6):463-9. https://doi.org/10.1016/S0109-5641(01)00069-0

24. Peutzfeldt A, Asmussen E. Resin composite properties and energy density of light cure. J Dent Res. 2005;84(7):659-62. https://doi.org/10.1177/154405910508400715

25. Nishitani Y, Yoshiyama M, Hosaka K, Tagami J, Donnelly A, Carrilho $\mathrm{M}$ et al. Use of Hoy's solubility parameters to predict water sorption/solubility of experimental primers and adhesives. Eur J Oral Sci 2007;115(1):81-6. https://doi.org/10.1111/j.1600-0722.2007.00430.x

26. Ortengren U, Andersson F, Elgh U, Terselius B, Karlsson $\mathrm{S}$. Influence of $\mathrm{pH}$ and storage time on the sorption and solubility behavior of three composite resin materials. J Dent. 2001;29(1):35-41. https://doi.org/10.1016/S0300-5712(00)00055-5

27. Chaves LP, Graciano FM, Junior OB, Pedreira AP, Manso AP, Wang $L$. Water interaction with dental luting cements by means of sorption and solubility. Braz Dent Sci. 2012;15(4):29-35.

28. Ferracane JL. Elution of leachable components from composites. J Oral Rehabil. 1994;21(4):441-52. https://doi.org/10.1111/j.1365-2842.1994.tb01158.x

29. Tanaka K, Taira M, Shintani H, Wakasa K, Yamaki M. Residual monomers (TEGDMA and Bis-GMA) of a set visible-light-cured dental composite resin when immersed in water. J Oral Rehabil. 1991;18(4):353-62. https://doi.org/10.1111/j.1365-2842.1991.tb00067.x

30. Bucuta S, Ilie N. Light transmittance and micro-mechanical properties of bulk fill vs. conventional resin based composites. Clin Oral Investig. 2014;18(8):1991-2000. https://doi.org/10.1007/s00784-013-1177-y

31. Lopes LG, Jardim Filho AV, Souza JB, Rabelo D, Franco EB, Freiras GC. Influence of pulse-delay curing on sorption and solubility of a composite resin. J Appl Oral Sci. 2009;17(1):27-31. https://doi.org/10.1590/S1678-77572009000100006

32. Wei YJ, Silikas N, Zhang ZT, Watts DC. Diffusion and concurrent solubility of self-adhering and new resin-matrix composites during water sorption/desorption cycles. Dent Mater. 2011;27(2):197-205. https://doi.org/10.1016/i.dental.2010.10.014 